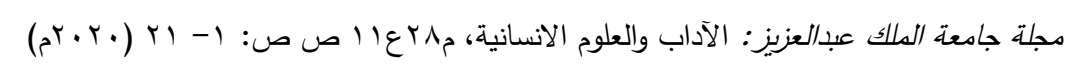

DOI:10.4197/Art.28-11.1

\title{
الاتساق النصي وخصائص الروابط الإحالية في قصيدة أندلسية لأحمد شوقي (دراسة لسانية إحصائية)
}

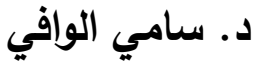 \\ أستاذ محاضر بقسم الأدب واللغتة العربية، كلية الآد/ب واللغات \\ جامعة العربي بن مهيدي، أم البواقي ، الجزائر \\ كلية الآداب واللغات، جامعة العربي بن مهيبي \\ أم البواقي، طريق قسنطينة، الجزائر • \\ البريد الاككتروني: louafi_2010@yahoo.com
}

مستخلص. تتاولنا في دراستنا هذه بالتحليل نموذجا شعريا، تمثّل في قصيدة "أندلسية" لأحمد شوقي، ركزنا فيهِ على

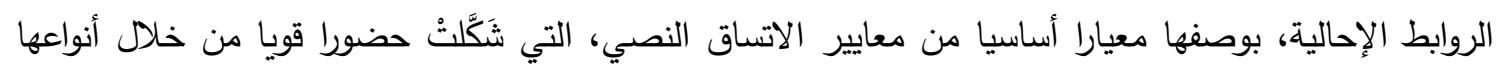
الثلاثة: (القبلية / البعدية / النصية)، مُجسّدةً علاقات التطابق بين أطراف الإحالة من مُحيلٍٍ ومُحال إليه. الكلمات المفتاحية: الاتساق - الإحالة - لسانية - إحصائية - قصيدة أندلسية

المعيار اللساني مجالا واسعا لدراسة الثعر من خلال نموذج تطبيقي مُختار هو قصيدة "أندلسية" لأحمد شوقي *، باعتبارها واحدة من أهم قصائده التي نُظمت في منفاه، مُتضمنة حنينا عميقا، ومُستهلكةً من ناظِمها طاقة شعرية كبيرة، جعلتنا كقراءٍ نلتمسُ نبرات الألم وعبارات الأمل، عبرَ مشاعرَ مختلفة تتضارب في صدره.

\section{تمهيد}

يعدّ الاتساق النصي من المعايير الأساسية التي من

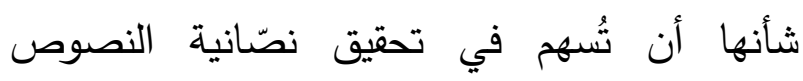
وكفاءاتها التواصلية، -التي يتباين حضورها من نص لآخر -، من خلال جملة من الآليات والوسائل، كالإحالة والحذف والاستبدال والفصل والوصل هل والاتساق المعجمي من تكرار وتضام، ليفتح لنا هذا 


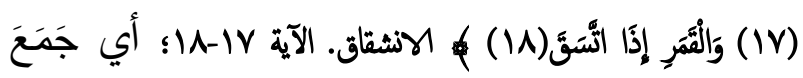

كما جاء في معجم "متن اللغة" لأحمد رضا (9019 (م) في مادة (و س ق): "اتِّقَ، يتَّسِقُ،

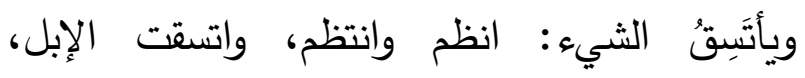
اجتمعت، واتساقُ القدر ، امتلأ واستوى ليالي الإبدار، والمتسق من أسماء القدر ، ومن كلامهم فلانٌ يسوقُ الوسيقة؛ أي يُحسنُ جمعها وطردها"(؟). يتضح لنا من خلال هذين التعريفين المعجميين أنّ مادة (و س ق) في الثقافة العربية أستخدمت بمعنى النظم والجمع والضم، وهذا يتفق إلى حدّ كبير مع التعريفات الاصطلاحية للاتساق، التي جيء بها لتكفل معنى التضام والجمع بين العناصر المُكونة للنصوص.

1-r- الالالة الاصطلاحية لمفهوم الاتساق: الاتساق من أبرز معايير النصية؛ إذ تقوم أدواته على الترابط الظاهري للنص صوتيا ومعجميا ونحويا، بحيث تتفاعل العناصر السطحية فيما بينها، فتحيلنا كلمات إلى كلمات أخرى (r)، فهو مرتبط بالبنية السطحية للنصوص، من خلال مستويات اللغة الأربعة: الصوتي/الصرفي/ التركيبي/ الدلالي، التي تتداخل فيما بينها لتُشكل نسقا لغويا مترابطا، فالاتساق بمفهوم عام: "يترتب على وسائل تبدو بها العناصر السطحية على صورة وقائع، يؤدي بها السابق إلى اللاحق، بحيث يتحقق لها الترابط الرصفي، وبحيث يمكن استعادة هذا الترابط" (؛)،
وسعيا منا لفك بعض شفرات هذه القصيدة المطولة وفق آليات التحليل اللساني النصي، نطرحُ إشكالا جوهريا تتدرج ضمنه أسئلة فرعية، سنحاول الإجابة عنها، مفادها:

كيف تجلت ظاهرة الاتساق النصي في قصيدة "أندلسية" بوصفه معيارا؟

وإلى أي مدى يمكننا الحُكم على تحقيقِ الاتساق في القصيدة بوصفه معيارا نصيا؟ وهل يمكننا اعتبار هذه القصيدة وحدة كلية متلاحمة في ضوء معيار الروابط الإحالية؟

1- الاتساق: Cohesion يُشَّل الاتساق معيارا هاما من معايير النصية، حيث يكفُل تماسكَّ النص وترابط عناصره، ليهتَم به علماء النص اهتماما بالغا، محاولين وضعَ تعريفٍ شامل لله، بتحديدِ الآليات التي تضمن تحقيق الاتساق داخل النصوص.

وقبل الخوض في تحديد تعريف الاتساق يجب أولا الوقوف على دلالته المعجمية في البيئة اللغوية العربية. 1- - - دلالة المصطلح المعجمية:

ورد في معجم "العين" للخليل بن أحمد الفراهيدي (1 V0 هـ) في مادة (و س ق): الوسق حِمْلٌ؛ يعني ستين صاعا، والوسَقٌُ: ضَمٌٌ الثيء إلى الثيء بعضهما إلى بعض، والاتسَاقُ: الانضمامُ والاستواءُ، كاتساق القدر إذا تََّ وامتلأ فاستوى، واسنتوسَقَتِ

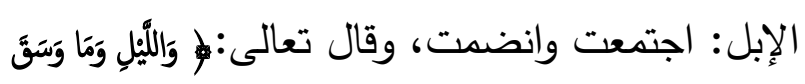


يُعرّف "محمد خطابي" الاتساق بأنه: "ذلك التماسك

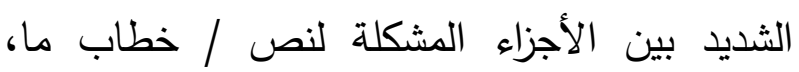
ويهتم فيه بالوسائل اللغوية (الثكلية)، التي تصل الترل بين العناصر المُكونة لجزء من خطاب أو خطاب

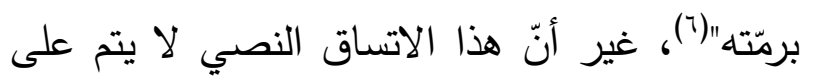

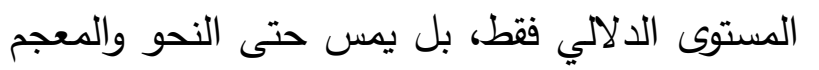

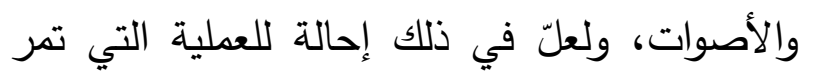
بها الكلمة قبل التلفظ بها، فهي تصور في البداية

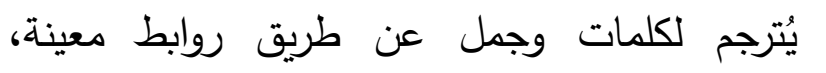

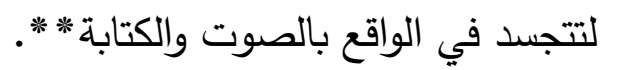

الذي هو عبارة عن أدوات وآليات تظهر في البنية السطحية للنصوص، للربط بين وحداتها اللغوية، فتُحيل كل واحدة منها إلى الأخرى، مُشكلة بنية لانية تراتبية متتابعة. الاتساق النصي بوصفه ربطُ نحوي هو تتابع بنائي ظاهري للنص، عن طريق استخدام وسائل الربط النحوية والقاعدية المختلفة، وبعبارة أخرى هو ارتباط وحدات النص من خلال مفاهيم نحوية، فتبدو عناصر بناء النص على صورة وقائع مُتتابعة، يؤدي مُعاي منها السابق إلى اللاحق، وهذا المعيار شكلي لني صناعي يدرس المباني للتوصل إلى المعاني(0). ترسيمة توضح لنا ذلك: (v)

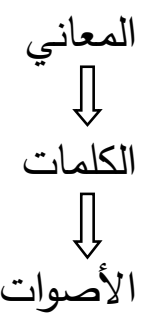

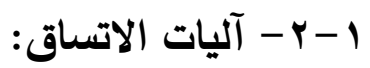
لا يتحقّقُ الاتساق إلاّ من خلال جملة من الآليات، هي:

\section{Reference الإحالة •}

Elimination الحذف •

\section{Substitution الاستبدال}

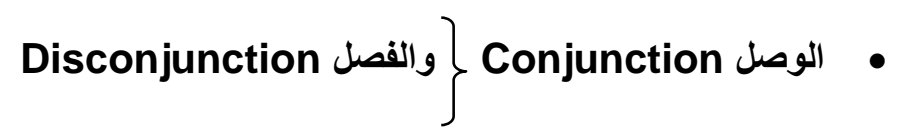

Collaction الاتساق المعمي : بثقيه: التضام

Frequency التكرار 
لاحقة أو عبارات أو مواقف لغوية أو غير لغوية" (^)،

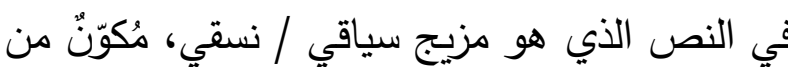
ألفاظ ومواقف وسياقات وأحداث دُوجّهة إلى القارئ بناءً على مقصد المتكلم. 1-r-1-1 - 1- عناصر الإحالة: تتكون الإحالة من أربعة عناصر ، وهي:

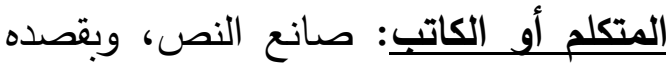
المعنوي تتم الإحالة إلى ما أشار .

اللفظ المُحيلُ أو العُنصُر الإحالي: ينبغي أنْ النّار. يتجسد إمّا ظاهرا أو مُقدّرا كالضمير، وهو الذي سيغير الاتجاه إلى خارج النص أو إو الونا

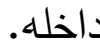

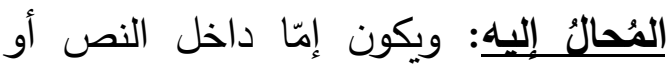
خارجه من كلمات أو عبارات أو دلالات. العلاقة بين اللفظ المُحيل والمُحال إليه: المفروض أنْ يكون التطابق مُجسدا بين اللفظ المُحيل والمُحال إليه(9). وإذا أردنا إسقاط هذه العناصر الإحالية على نص

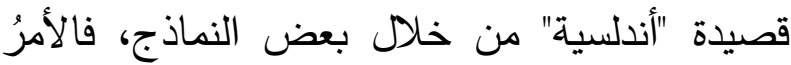

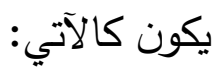

وفي مقالنا هذا بالتحديد سنركز بالدراسة والتطبيق على آلية واحدة هي الإحالة، بكشف سمات تجليها

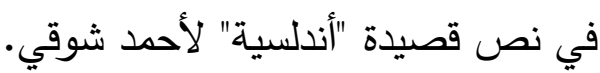
Reference النص بنية شاملة، مكونة من وحدات لغوية تشكل كيانه الداخلي، محكومة بمبدأ التتابع والترتيب، تبعا لطبيعة الحدث الذي تجسّده، وهذه الوحدات لا بدّ لها من ترابط محكم، لتتفاعل مع بعضها البعض وتُشكّل

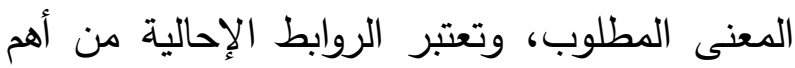
العوامل المساهمة في اتساق النصوص واتحاد عناصرها، فما المقصود بالإحالة كمصطلح? وفيم تتمثل الروابط الإحالية في قصيدة أندلسية لأحمد شوقي؟ - ن الت نالت الإحالة اهتمام الباحثين المتخصصين في الدرس اللساني قديما وحديثا، حيث عالجوا قضاياها من خلال الروابط والضمائر وأدوات الإثارة، محاولين إعطاء تعريف شامل لها، بوصفها "علاقة معنوية بين ألفاظ معينة، وما تُشير إليه من أشياء أو لو

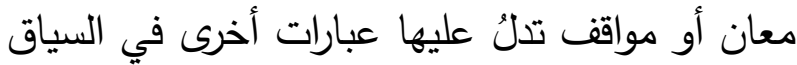

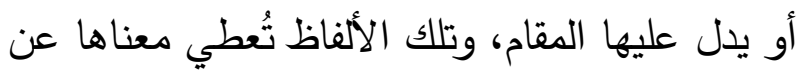
طريق قصد المتكلم، مثل الضمير واسم الإثارة والاسم الموصول، حيث تشير إلى أشياء سابقة أو 


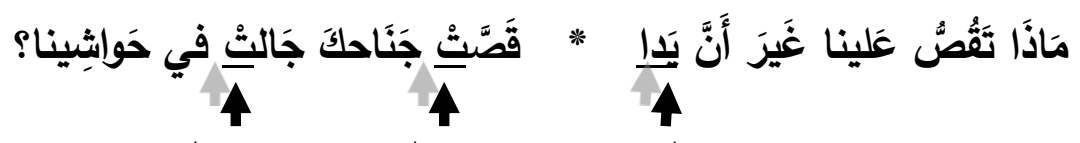

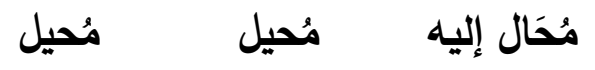

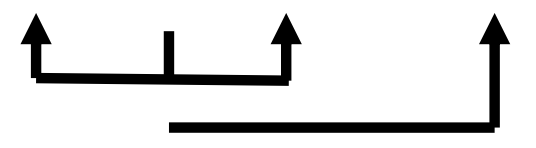

علاقة تطابق

فالمتكلم هو الثاعر "أحمد شوقي"، والمُحيل "تاء أما المُحال إليه فهو "اليدُ" التي قامت بالفعلين، التأنيث الساكنة" المُقترنة بالفعلين "قَََّّ" و "جَالَ"، والعلاقة بينهما تطابق. يقول الشاعر كذلك:

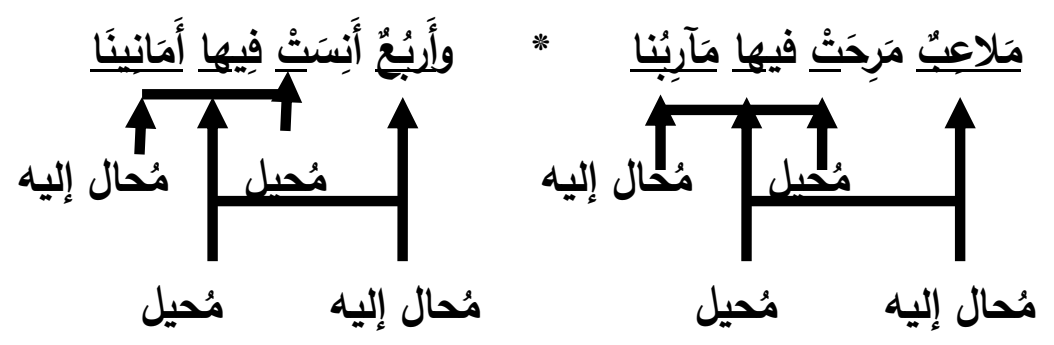

علاقة تطابق

جمع البيت أربع علاقات إحالية، جسّدتها "تاء على "الملاعب"، و "اللهاء" الثانية في عجز البيت التأنيث الساكنة" في صدر البيت، والتي تُحيل إلى التي تعود على "الأربُعِ، وتربط بين عناصر كل "مآربنا"، ومثيلتها في عجز البيت تُحيل إلى علاقة إحالية علاقة تطابق. "أمانينا"، وكذا "الهاء" في صدر البيت التي تعود 


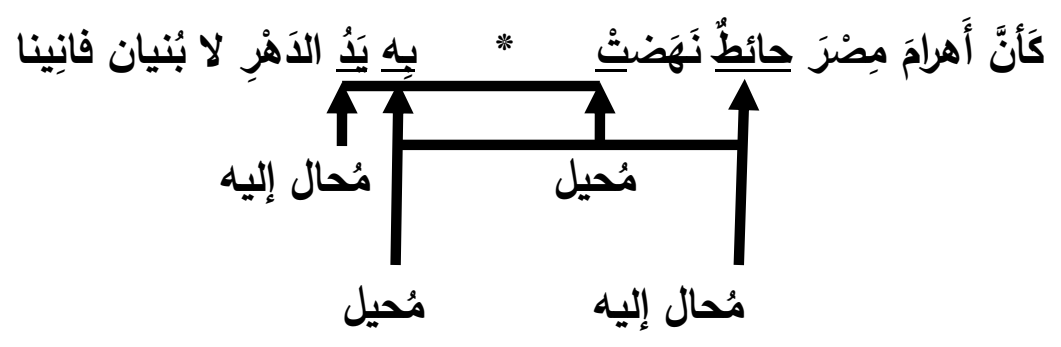

علاقة تطابق

اشتمل البيت على علاقتين إحاليتين، متّلتهما تاء و"الهاءُء" في "بِِهِ" التي تعود على "حائطٍٍِ"، وعلاقتهما

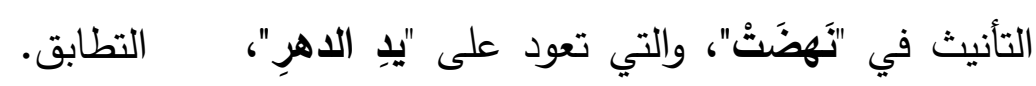
يقول الثاعر أيضا:

يُفني المُلوكََّ ولا يُبقي الأواوينَا

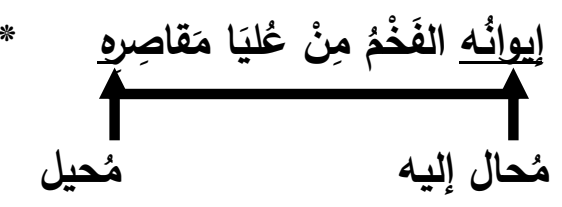

\section{علاقة تطابق}

• إحالة إلى سابق أو مُتقدم Anaphora: وذلك

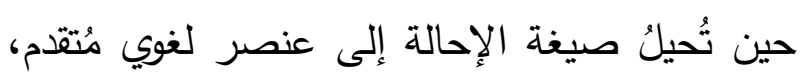

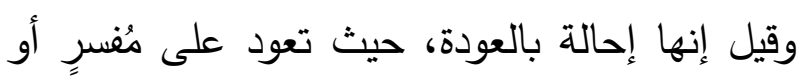
عائدٍ سبقَ التلفظظَ (الإحالة القبلية). • إحالة إلى لاحق Cataphora: وذلك حين يُحيلُ عنصرُ لغوي أو مكونٌ ما إلى تالِ له في في النص، وقيل هي تعودُ على عنصرٍ مذكور بعدها في النص أو لاحق عليها (الإحالة البعدية) (·').
الإحالة كانت في صدر البيت، بين "الهاءِ" في "مقاصِرِهِ"، التي تعود على "الإيوانِ"، وعلاقتهما تطابق. (الإحالة: 1-r-1-r-1- بحسب الاتجاهات: وهي نوعان اثنان، هما: أ- إحالة نصية: داخل النص، وتثمل نوعين من الإحالات: 


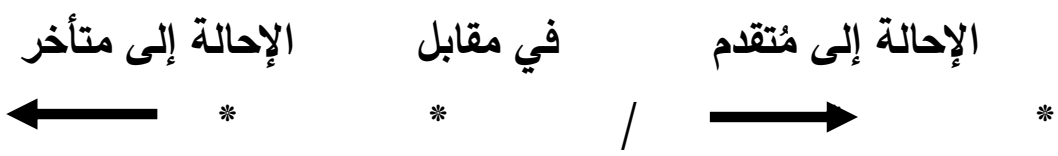

ب- exphora وهي إحالة عنصر عاحبه المتكلم (')، والثكل الآتي يوضحُ أهم أنواع لغوي إلى عنصر غير لغوي موجود في المقام الإحالة:

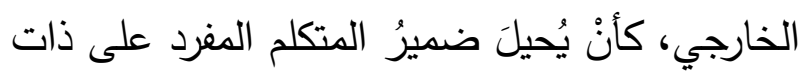
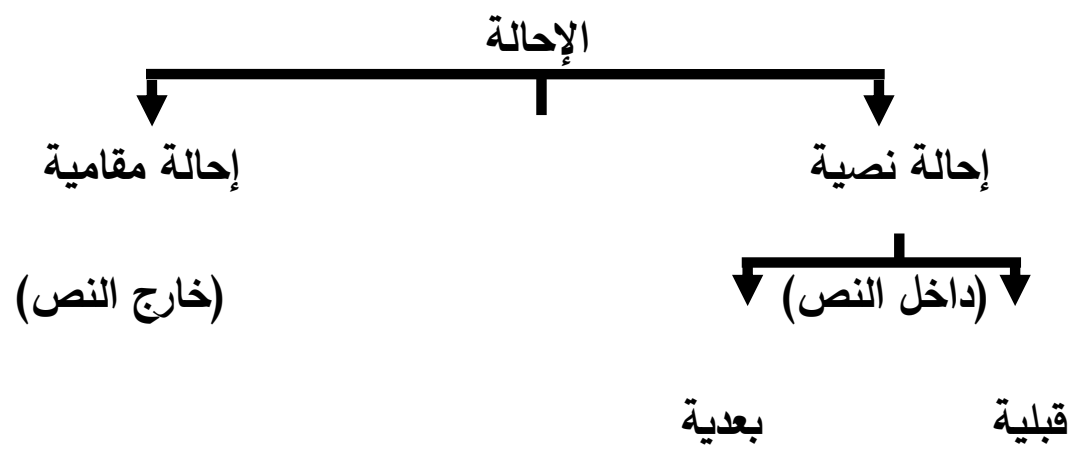

إذا عدنا إلى القصيدة نجد أنّ الإحالة على أساس نماذج من القصيدة، حاولنا فيها التطبيق على الاتجاهات لها دور كبير في تماسك النص وبنائه الإحالة بأنواعها الثلاثة: الداخلي، بتجسيد وحدته اللغوية، وفي الجدول الآتي

الجدول رقم 1 +. أنواع الإحالة في قصيدة "أندلسية"

\begin{tabular}{|c|c|c|}
\hline التعليق & نماذج من القصيدة & نوع الإحالة \\
\hline 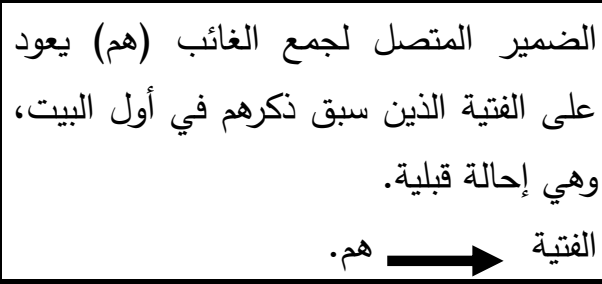 & 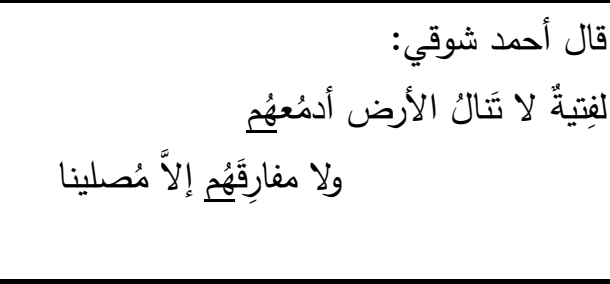 & إحالة قبلية \\
\hline 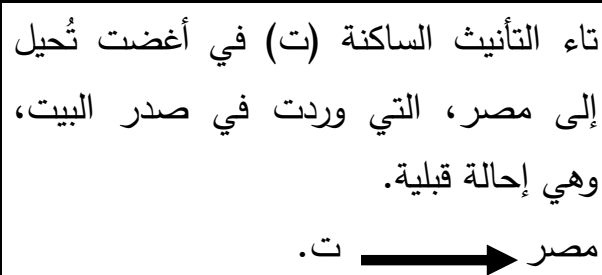 & 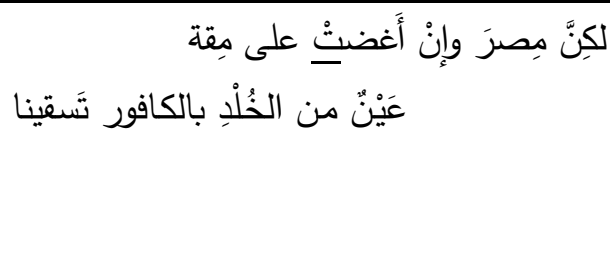 & إحالة قبلية \\
\hline
\end{tabular}




$$
\text { سامي الوافي }
$$

\begin{tabular}{|c|c|c|}
\hline 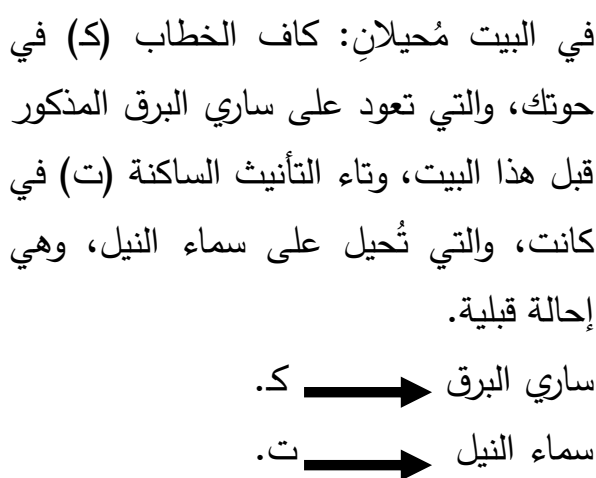 & حتى حَوَتْكَ سماءُ النيلِ عاليةًَ & إحالة قبلية \\
\hline 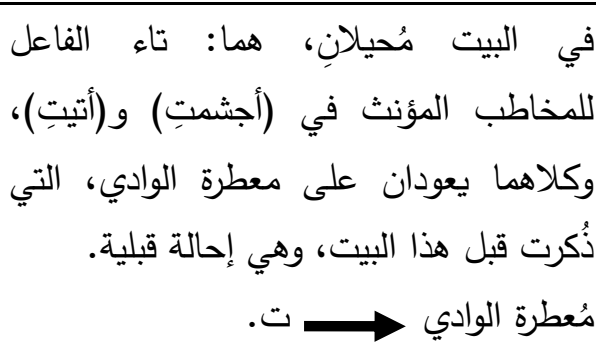 & 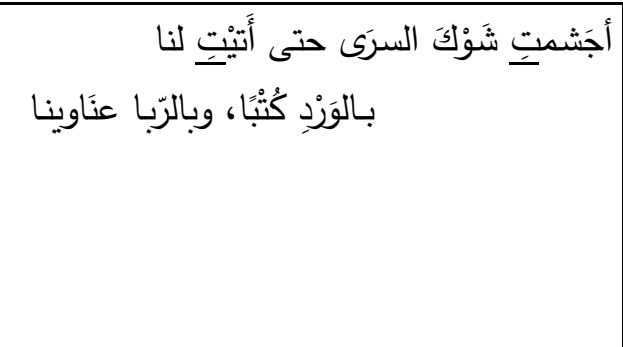 & إحالة قبلية \\
\hline 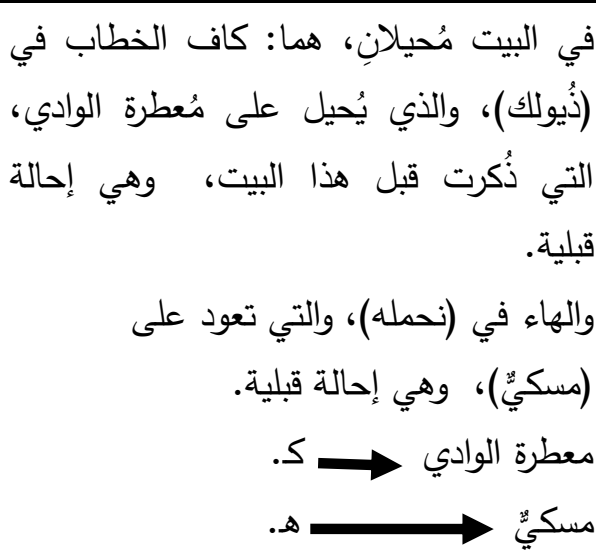 & هل من ذيولكِ مسنكِيُّ نُحَمِّلْهُ & إحالة قبلية \\
\hline 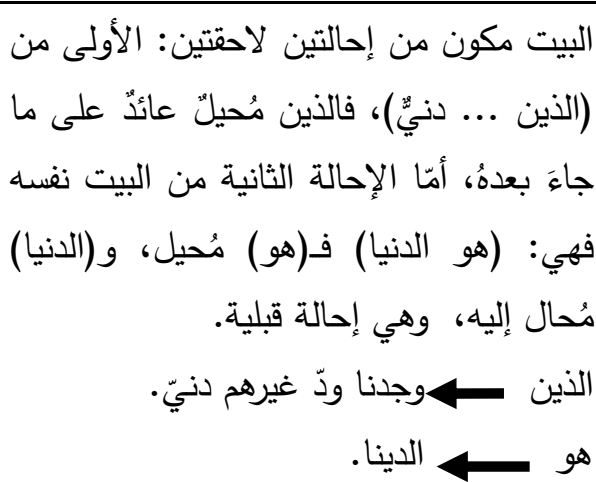 & إِلى الذين وجَذْنـا وُدَّ غيرهِهُ & إحالة قبلية \\
\hline في الإحالة البعدية مُتجسدة في هذا البيت تحديدا & كلٌّ رَمتْهُ النوى ريشَ الفراقَ لنَا & إحالة بعدية \\
\hline
\end{tabular}




\begin{tabular}{|c|c|c|}
\hline النوى المذكورة بعده، وهي إحالة بعدية. & & \\
\hline 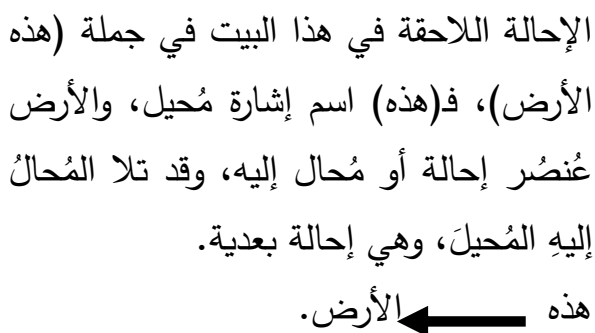 & وهذه الأَرضُ من سَهْلِ ومن جَبلٍ & إحالة بعدية \\
\hline 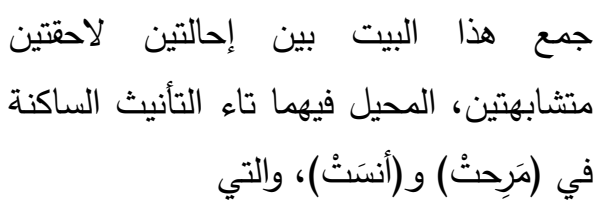 & مَلاعبٌّ مَرحتُ فيها مآربنا & إحالة بعدية \\
\hline 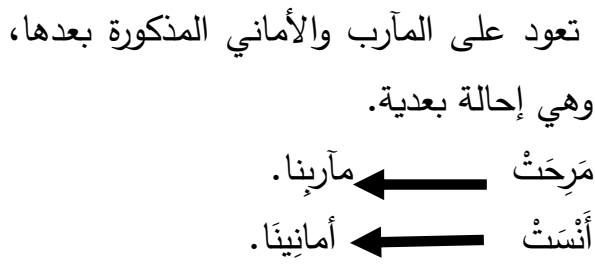 & & \\
\hline 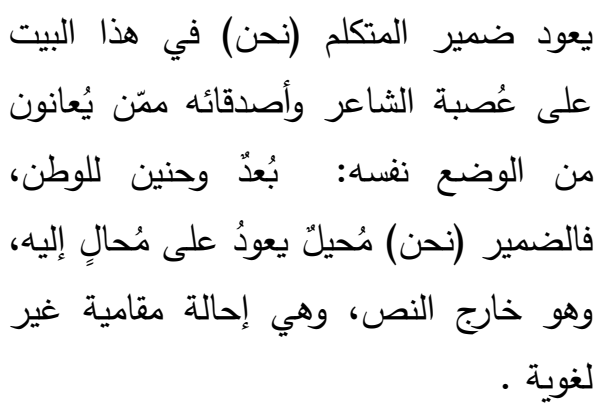 & 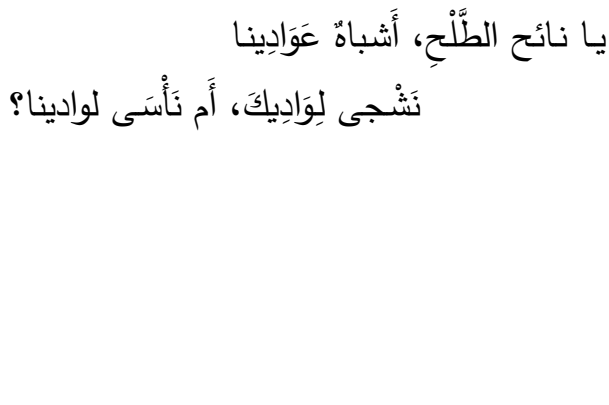 & إحالة مقامية \\
\hline وإلى مُحال إليه واحدا البيت إحالات مقامية تعود كلها & بتـتا ـنقاسِي الدواهي من كواكِبها & إحالة مقامية \\
\hline
\end{tabular}

شهدت قصيدة أندلسية تتوعا في التوظيف الإحالي، القصيدة، فرغم كونها لم تخرج عن مُشيرين اثثين:

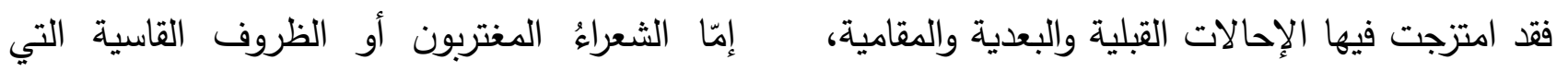

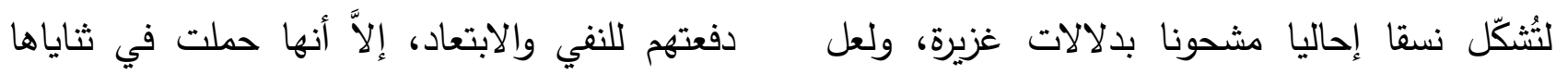

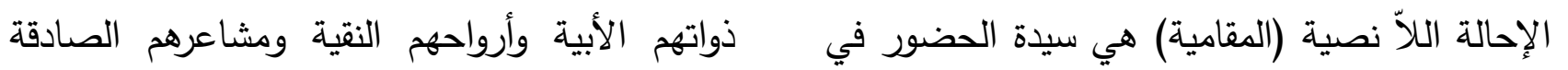


تجاه وطنهم، وعبَّرت كذلك عن الصلة الروحية •إحالة ذات مدى قريب: وتجري في مستوى الجملة الواحدة، حيث لا توجد فواصل تركيبية الممتدة بينهم وبين وطنهم، فهذا النوع من الإحالة وعناه جملية.

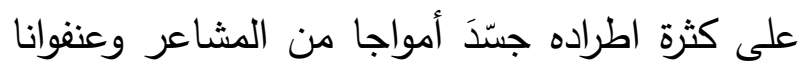

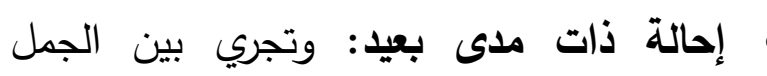

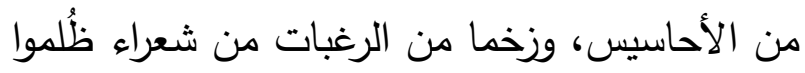
المتصلة والمتباعدة في فضاء النص، وهي ونجي لهين وسُجنوا وهم أحرار في وطن ليس وطنهم، وبين أهل تتجاوز الفواصل أو الحدود التركيبية القائمة بين ليسوا بأهليهم.

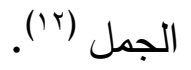
وقد ورد النوعان في القصيدة المدروسة بشكل مكثف

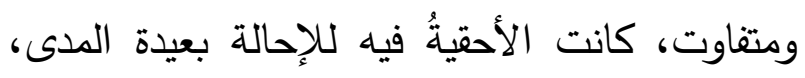

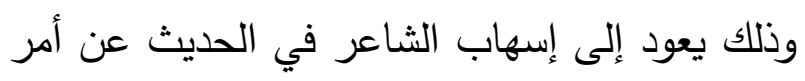

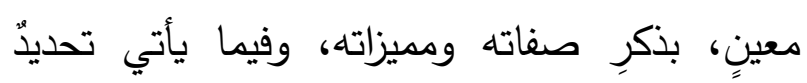
لبعض نماذج الإحالتين (قرببة المدى / بعيدة المدى) بعاته من قصيدة "أندلسية" لأحمد شوقي، على سبيل الذكر لإني لا الحصر :

$$
\begin{aligned}
& \text { } \\
& \text { العنصر الإحالي ومُفسرهِ: وهي نوعان اثنان، هما: } \\
& \text { نماذج عن الإحالة قريبة المدى: قال أحمد شوقي: }
\end{aligned}
$$

واللَسيلُ لَو عَفَّ، والمِقدارُ لو دينًا

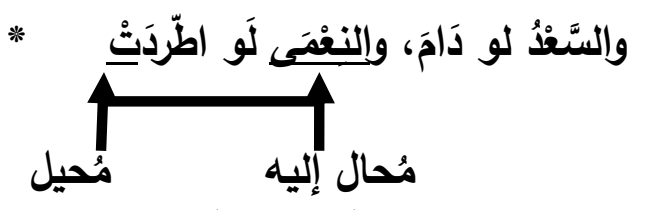

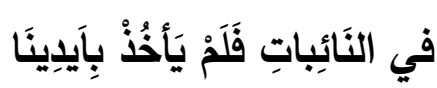

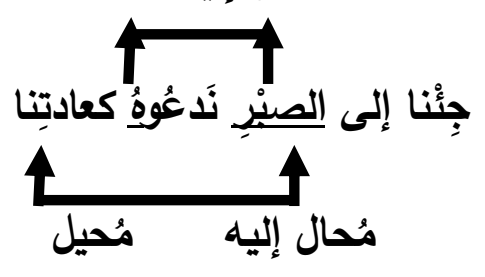

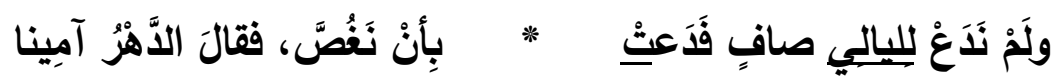

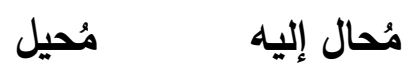


لكن كيف تكون الإحالاتُ هنا إحالاتُ ذات مدى قريب، وبين المُحيل والمُحال إليه فواصل من أدوات إلات ذات ذات

$$
\text { وصفات؟ تربك، وبين }
$$

الجواب يكمن في طبيعة هذه الفواصل، فلو كانت حرفا أو اسما فلا تؤخذ بعين الاعتبار، ولا تؤثر في لوني

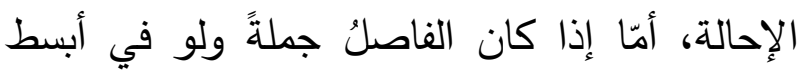

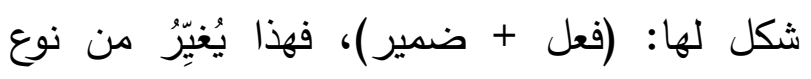

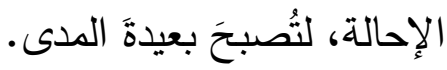

تُبينُ لنا هذه الأمثلة الثلاثة النوعَ الأولَ من الإحالة

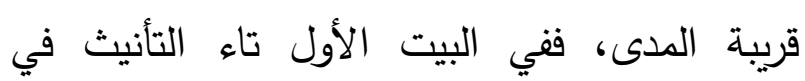

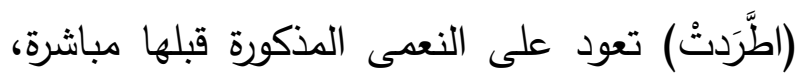

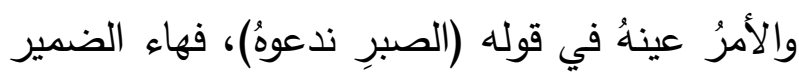
الغائب في الفعل (ندعوه) يعود على (الصبرِ)، وقد فئد

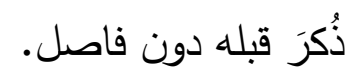

\section{نماذج من الإحالة بعيدة المدى: قال أحمد شوقي:}

هُحِيل

\section{$\downarrow \downarrow \downarrow$}

للناسِ، كانَت لََهُهْ أَخْلاقُهْهْ دِينَا

مُحيل مُحيل

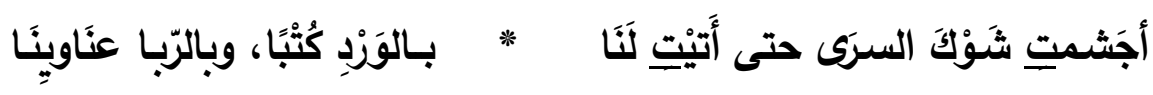

مُحيل
* عَلى جَوانِبِهِ رَفَّتُتْ تَمائمِمُنا

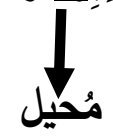

\section{$\downarrow$}

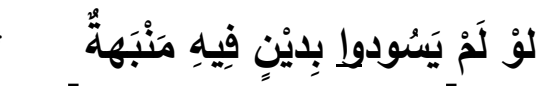

$\downarrow$

مُحيل

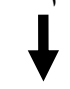

مُحيل
المُحيلِ والكُحالُ إليِهِ جملتان، فهي إحالةُ قبلية بعيدةُ المدى.

أمّا النموذج الثاني تجسّد المُحيلُ فيه في "واو" الجمع في الفعل (يسودوا)، وفي ضمير الغائب للجمع (هم) في جملة (كانت لهم أخلاقهم دينا)، وهذه الضمائر تعودُ على الفِتيِة الذين سبق ذكرهم في البيت السابق 
حيث أجملوها في ثلاث وسائل هي: الضمائر / أسماء الإشارة / أدوات المقارنة، وهو الرأي نفسأ الذي تبناه العرب المحدثون، فنجد الباحث "أحمد الإداء

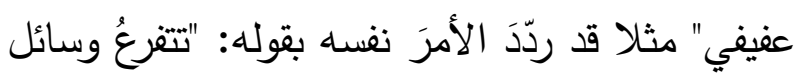

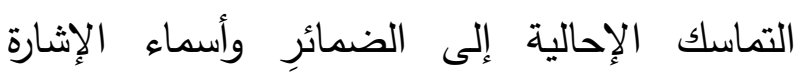
والموصولة وأدوات المقارنة، مثل التشبيه، وكلمات الاتلية

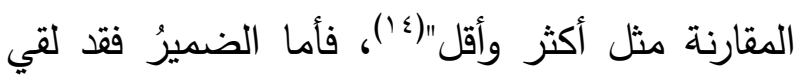

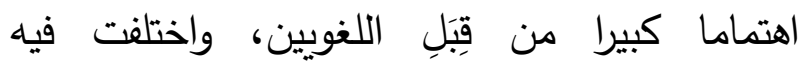
التعريفات قديما وحديثا، فلا يخلو نص من من وجود

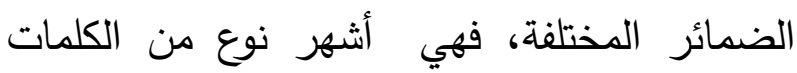

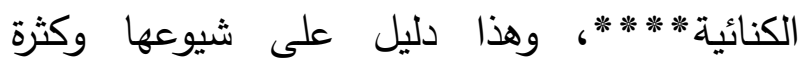
استخدامها نصيا أو شفويا للإثشارة إلى شيء ما.

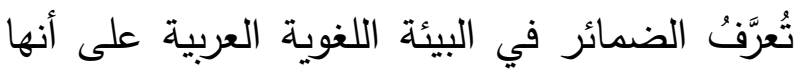

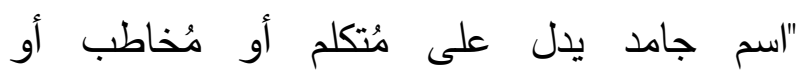
غائبٍ"(10)، فهو اسم جامد لاستحالة تصريفه مع لـائم الضمائر المختلفة، يُحيلُ إلى شخص فئ معين أو لأن

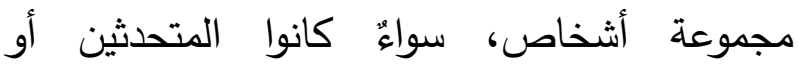

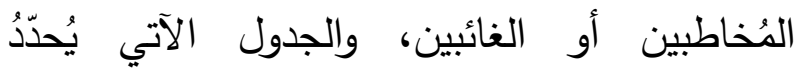
إحصائيا مجموع الضمائر الواردة في القصيدة:
لهذا البيتِ، وقد فَصَلَ بين المُحيل والمُحال إليه جملة استئنائية، فهي إحالة ذات المدى البعيد.

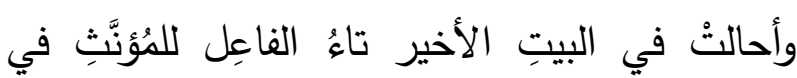

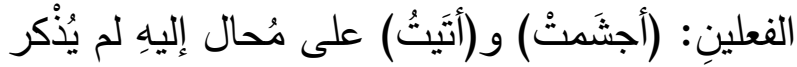

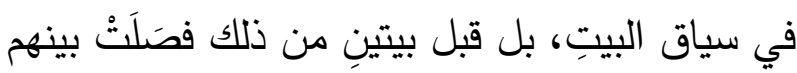
مجموعة جُمل، فهي إحالة قبلية بعيدة المدى. 1-r-r-r- الوسائلُ الإحاليةُ

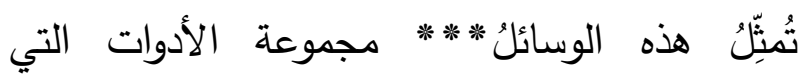

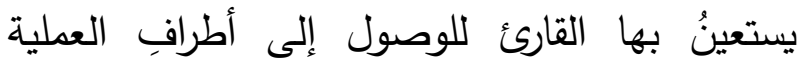

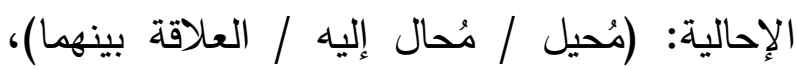
فهي "تلك العناصر التي يُعتمدُ عليها لتحديد المُحال

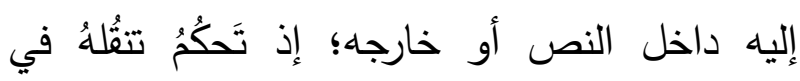
فضاءات النص من أجل تفسيرها، فلا تملك دلالة

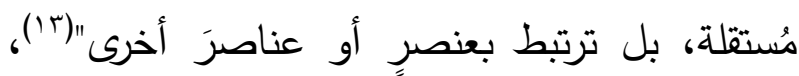

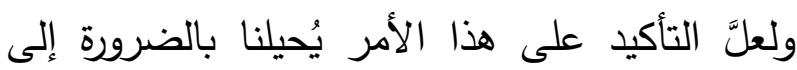

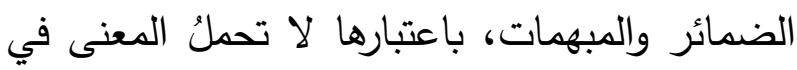

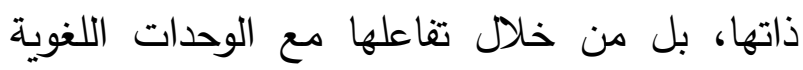
المُحيطة بها. وقد اختلف الباحثون في تحديد مجموع الوسائل الإحالية، وإنْ كانوا قد اتفقوا في الإطار العام لها،

الجدول رقم r . : نِسبُ الضمائر في قصيدة "أندلسية":

\begin{tabular}{|c|c|c|c|c|c|c|c|c|c|}
\hline & & & غغائب & & & & & المتكلم & \\
\hline & هنُ & هم & هما & هي & هو & أنتم & أنت & نحن & الضمير \\
\hline r97 & 7 & $1 \pi$ & $\bar{r}$ & 79 & $\overline{v o}$ & $\bar{\mu}$ & $\overline{Y Y}$ & 1.0 & تكرارها في \\
\hline $1 \ldots$ & $\overline{. Y, \cdot Y}$ & $\varepsilon, \xi$ & $1, \cdot 1$ & $r r, r$ & $\overline{Y \theta, r}$ & $1, .1$ & $\overline{V, \varepsilon}$ & $\overline{r \theta, \theta}$ & النسبة \\
\hline
\end{tabular}


نُلخص الجدول في الشكل البياني الآتي:

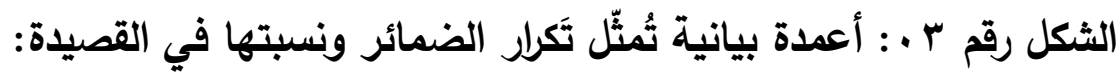

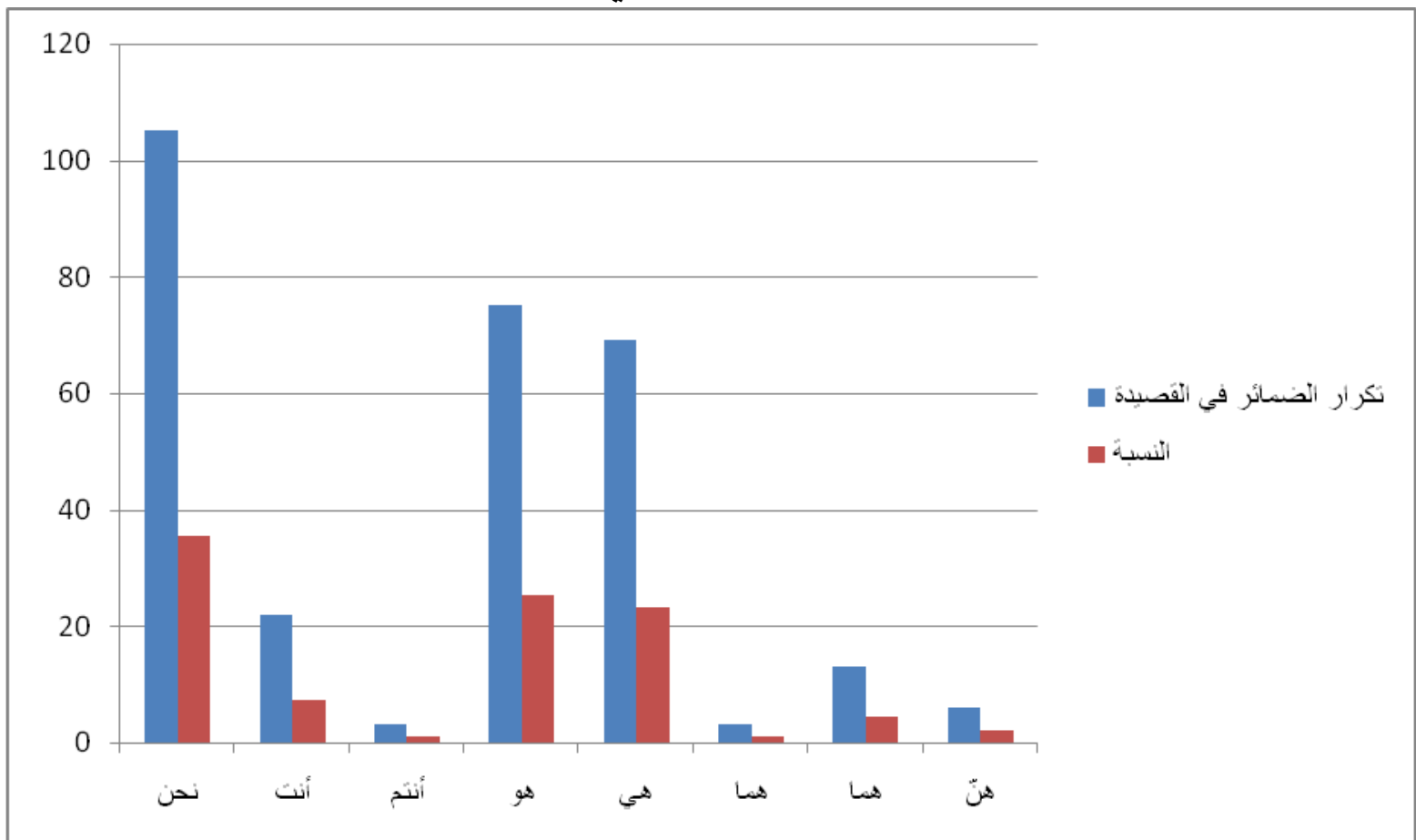

بناءً على معطيات الجدول والثكل البياني نلاحظُ يمشي عليها أرضهه، وأنّ روابيها هي روابيهج، وأنهج

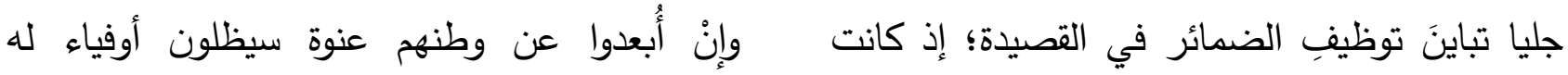

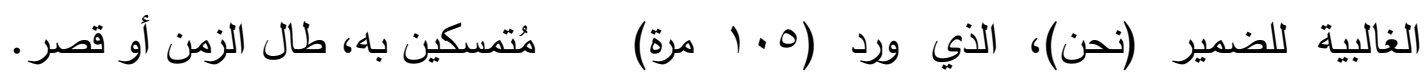

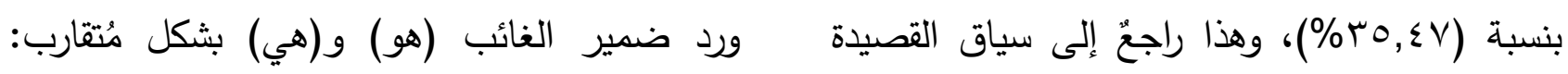

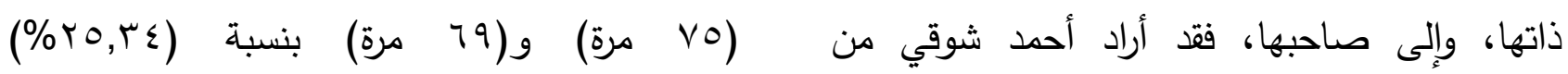

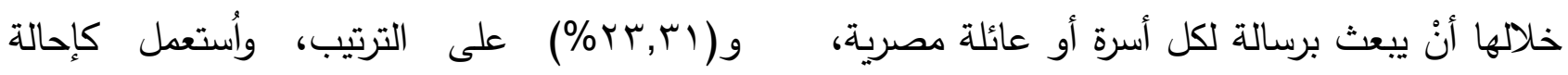

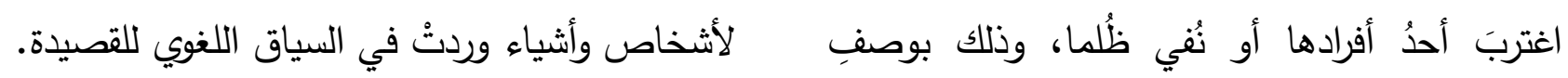
حنينه والوضع الذي يُعانيه في الغربة، ورغبته في أمّا استعمال ضمير المخاطب (أنتَ) للمذكر و (أنتِّ)

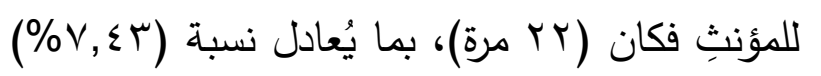
العودة إلى رحاب مصر وأهاليها.

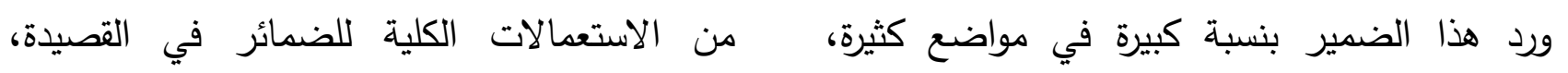

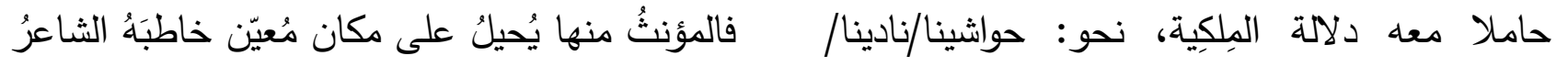

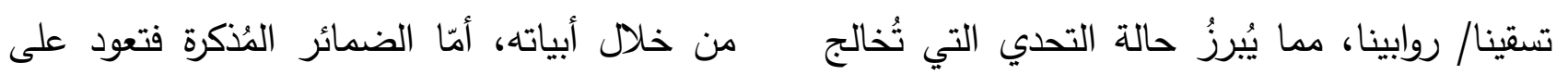

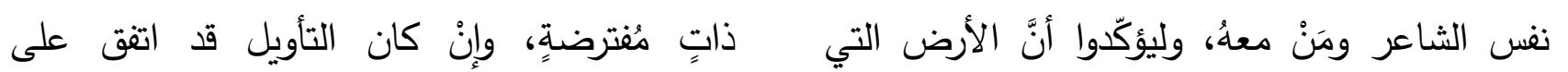


أمّا بخصوص المُبهماتُ كأسماء الإشارة والأسماء

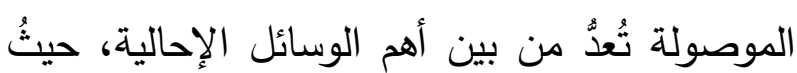

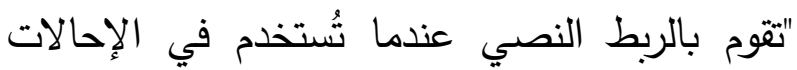
القبلية والبعدية، وتُشاركُ الأسماءَ الموصولةَ بقيةً

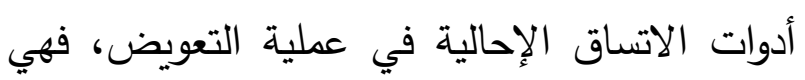
ألفاظ كنائية لا تحمل دلالة خاصة، وكأنها جاءت الإله تعويضا عما تُحيلُ إليهِه" (1')، فهي لا لا تحْمِلُ معناها في ذاتها، بل من خلال تفاعلها مع ما جاورها من الوحدات اللغوية، فكلا الاسمين يُحققان ربطا اتساقيا،

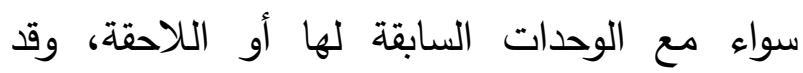
لاحظنا ندرة في استخدام أسماء الإشارة والأسماء لوحاء الهاء الموصولة، التي وردت مرة واحدة فقط في القصيدة ككل، وذلك في قوله:

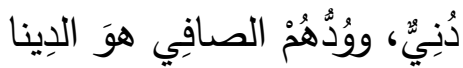

* ق قَبلَ القياصِرِ دِنَّاها فراعِينا

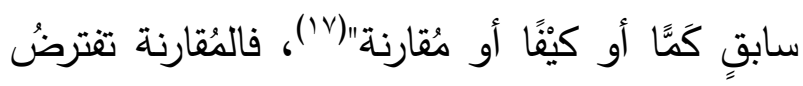
وجود طرفين أو أكثر ، لتنَّ المقارنة بينهما من خلاد اله

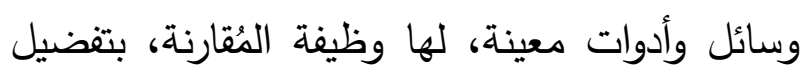

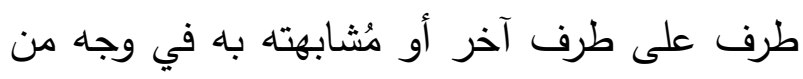

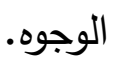
وبإسقاط هذه المفاهيم النظرية على نماذج مختارة من القصيدة ييرُزُ لنا نوعان من المقارنة: المقارنة عن هن طريق التفضيل والمقارنة عن طريق التشبيه.
مُخاطبته لشخصية تاريخية، هو المُعتمد بن عباد،

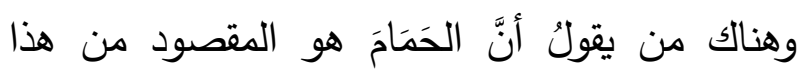

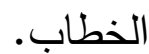
وردت في القصيدة ضمائر أخرى بنسبة أقل من سابقاتها: (أنتم/هما/هم/ هنّ)، حيث تكرروا تِباعا:

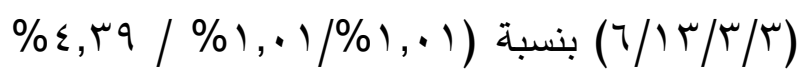

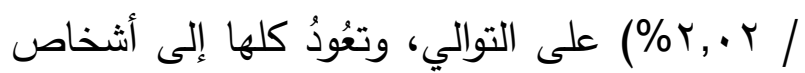
وأشياء وأحداثٍ مُدرجة في القصيدة. ومنه فالضمائر باختلافها هنا في القصيدة شكّلتُ حلقة أساسية من حلقات الإحالة، وقد اعتمدها الثاعر بشكل كبير لضبط المعاني، وإيصالها مترابطةً / مُتناسقةً / مفهُومةً للمتلقين.

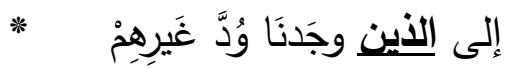

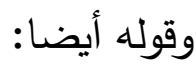
وهذِ الأرضُ مِنْ سهلٍ ومنْ جَبلٍ

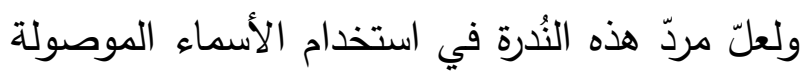

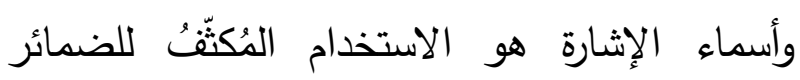

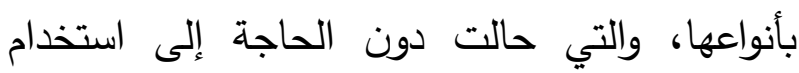
الصلة والإشارة.

أمّا الئقارنة فهي الوسئة الوهيلة الثالثة من الوسائل الإحالية، حيث تقوم على اليُقارنة بين الأشياء

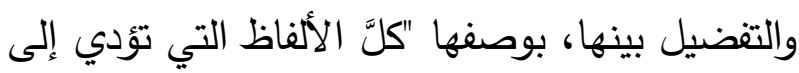
المُطابقة أو المُشابهة أو الاختلاف أو الإضافةُ إلى لى لئل 


$$
\text { • المقارنة عن طريق التفضيل: في قول الشاعر : }
$$

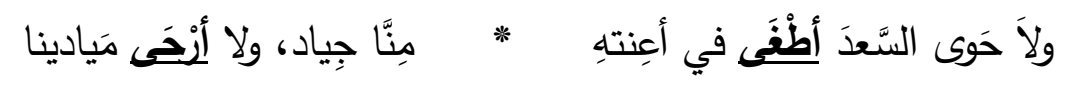

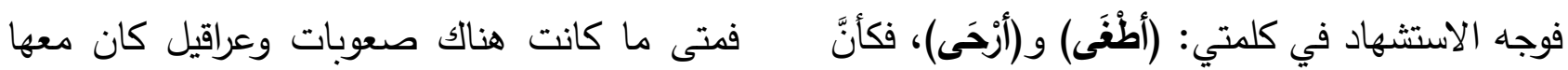
الثاعر يقارنُ نفسأُ وباقي الثعراء المهجيين بغيرهم التجلد والصبر والوفاء.

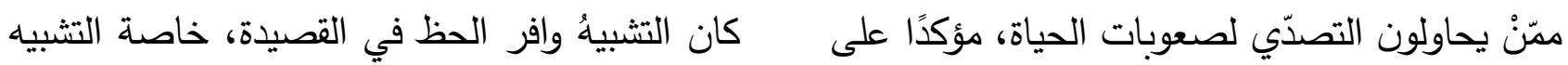
صلابتهم وأفضليتهم، وأنّ الحُروب ودروب الوغى بالأدوات (الكاف/كأنَّ)، وبالأفعال (تماثل/ تحسبها)، أهونُ ألف مرة مما يعانونه في غربتهم، فهذا البيتُ وتمثيلُ ذلك:

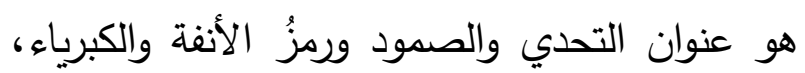

الجدول رقم ع : : نماذج التثبيه في القصيدة:

\begin{tabular}{|c|c|c|c|}
\hline نماذج من القصيدة & تواتره & \multicolumn{2}{|c|}{ نوع التشبيه } \\
\hline لمُ نَسْرِ مِنْ حَرَمٍ إلالّ إلى حَرَمٍ & سبع مرات & الكاف & أداة \\
\hline 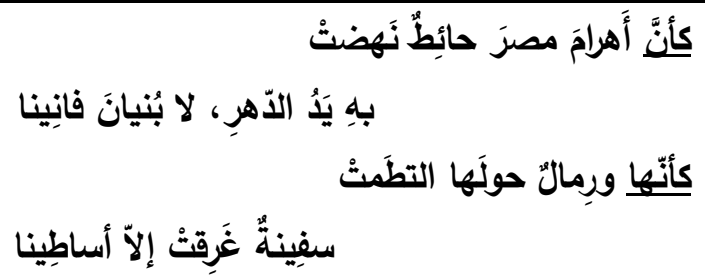 & 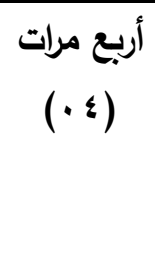 & 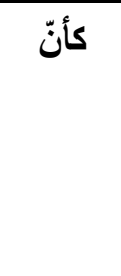 & \\
\hline 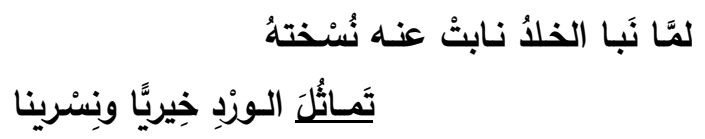 & مرة واحدة & تماثل & \\
\hline 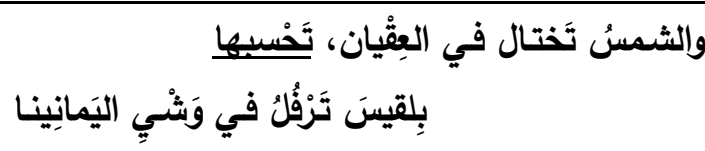 & مرة واحدة & تحسبُهُ & \\
\hline
\end{tabular}


نُلخص الجدول في الثكل البياني الآتي:

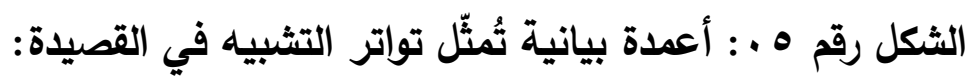

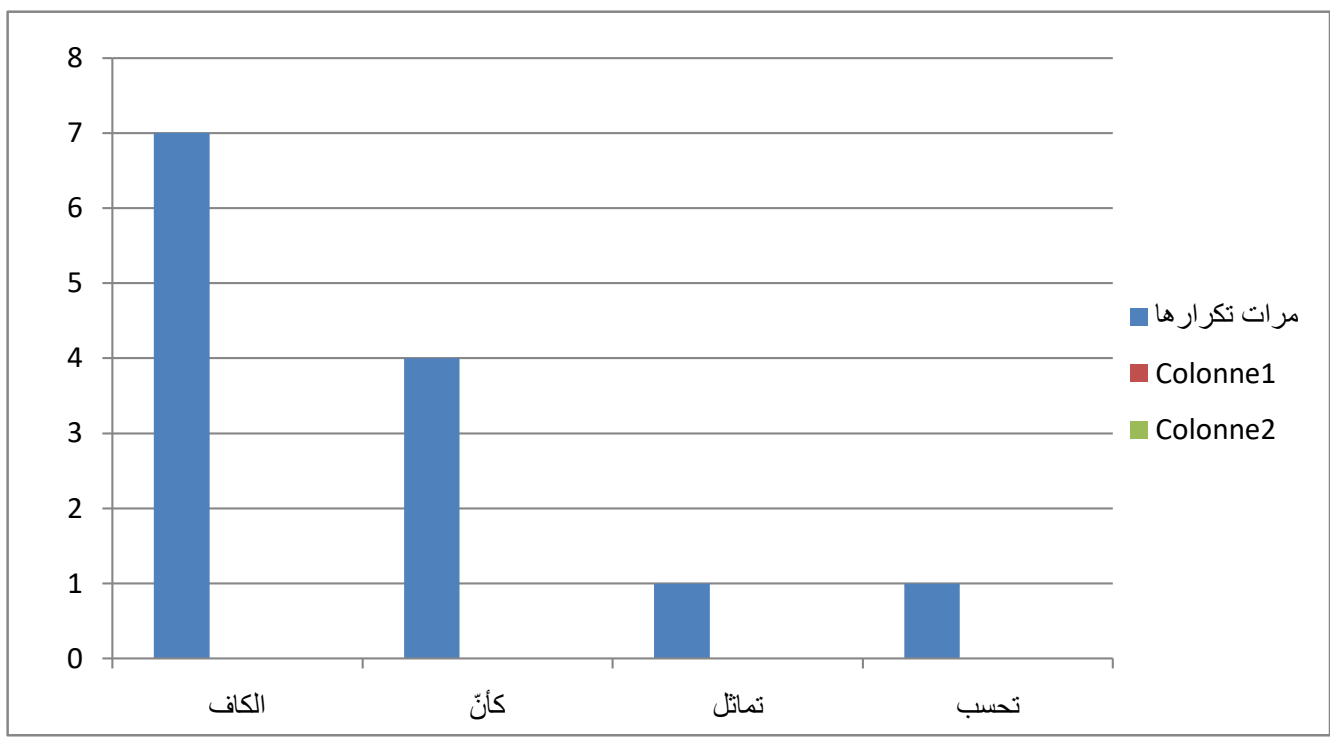

يُبيّن الجدول والأعمدة البيانية أنَّ "كاف التشبيه" وأشياء، علَّهُ بذلك يوفيها حقَّها من الوصفِ، لكن

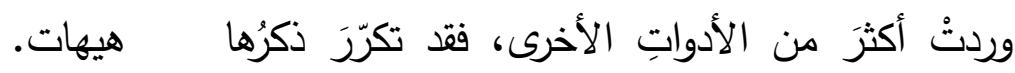
الخاتمة

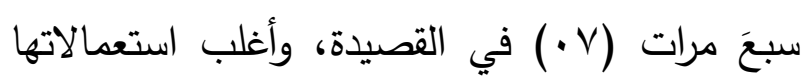

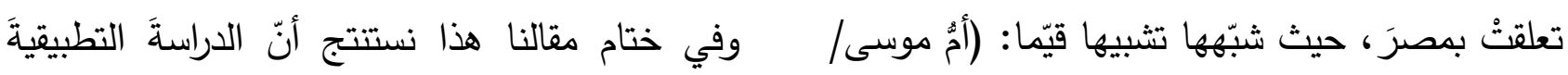
للاتساق النصي في قصيدة "أندلسية" لأحمد شوقي الني كشفت على أنهُ آلية أساسية في تحقية التئي الترابط والتماسك داخل النص، لارتكازه على البنية الداخلية

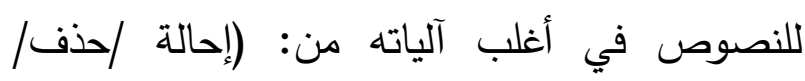
الأنيا/الكرج)، وفي غيرها حديث عن نفساه ومن معهد

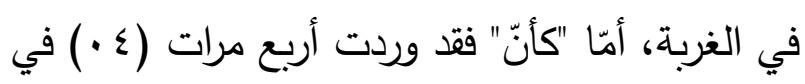

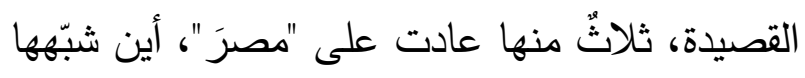

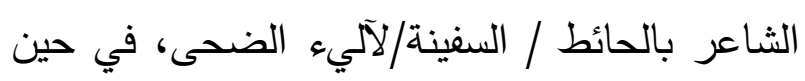
استبدال/فصل ووصل/اتساق معجمي بشقيه: التكرار

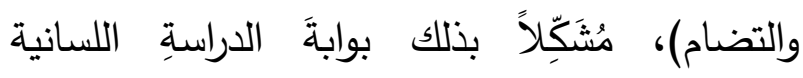
"التشبيهُ بالأفعال" تجسّدَ في الفعلينِ:

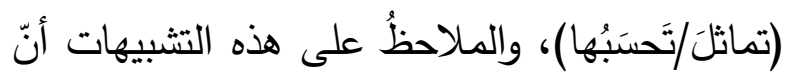

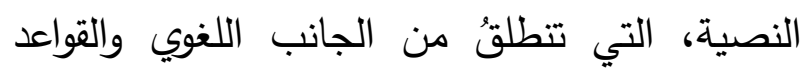
مُعظمَها يدورُ حول مصرَ، باعتبارها موطِن الثاعرِ وهرِ

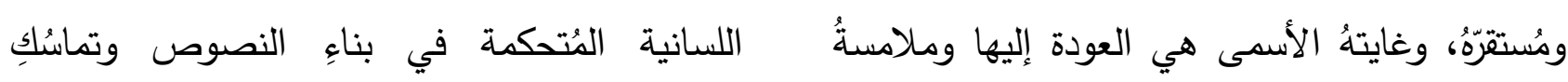

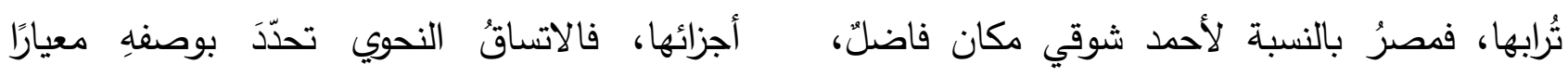

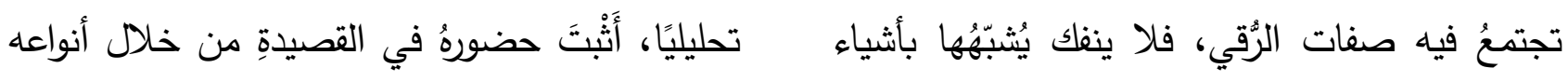




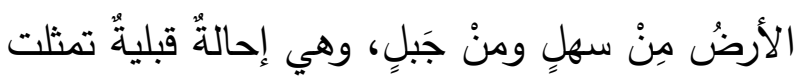

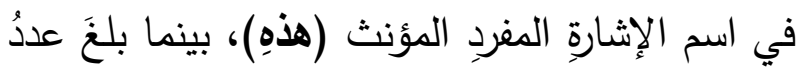

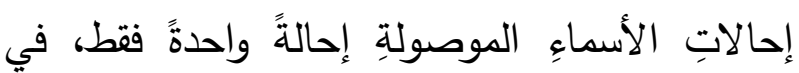

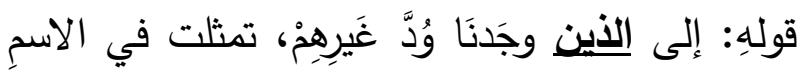
الموصولِ (الذينَ)، وباعتبارِ أنَ الأسماءَ الموصولةً

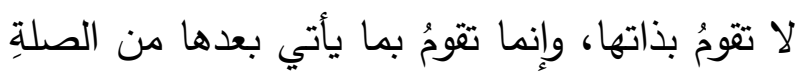

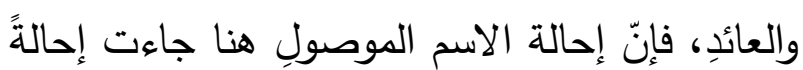

بعديةً. - الإحالة الإشارية الواردة في القصيدةٍ ذات مدى قريب؛ إذ لا يتعدى الفاصلُ بين اللفظٍ المُحيل واللفظٍ

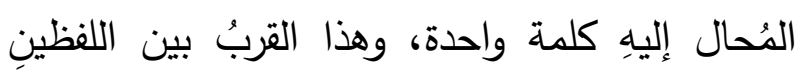

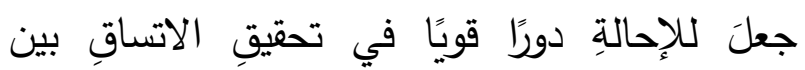
اللفظينِ.

- حفلَ نصُ القصيدةِ بنوعين من المقارنتِ:

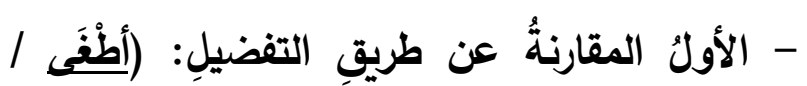

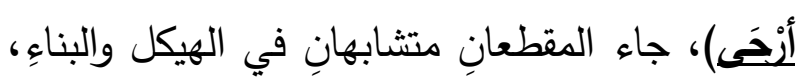

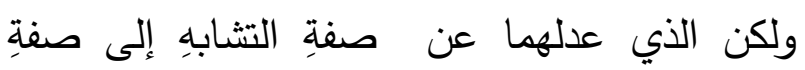
التقابلِ هو تقابلُ الفعلينِ (أطُفَى / أزْحَى).

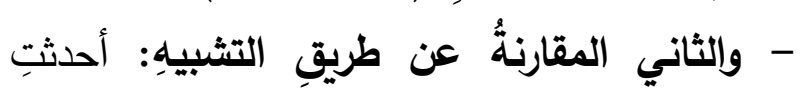
الجملُ المقارنُ بينها بالتشبيهِيه: مثلُ التشبيهِ بالأدواتِ

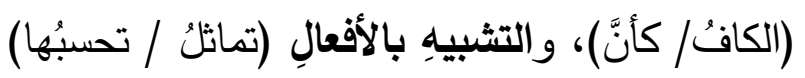

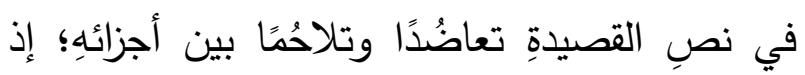

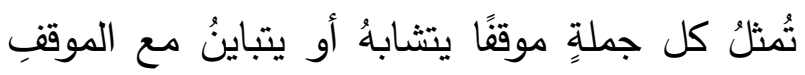

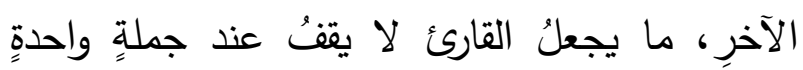

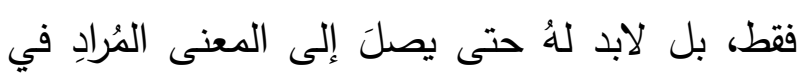

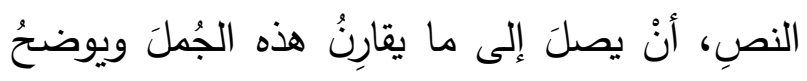

الثلاثة: (قبلي / بعدي / نصي)، مُجسّدا لعلاقاتِ

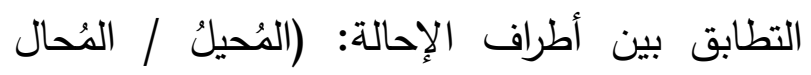

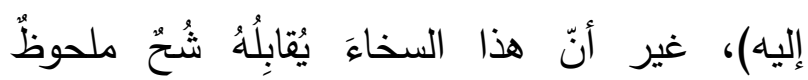
للوسائلِ الإحالية من أسماء إثارة وأسماء موصولة الئلة وأدوات المقارنة. نجملُ هذه النتائج التطبيقية في النقاط الآتية: الاتساقُ النحوي (الإحالةُ):

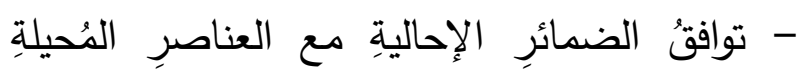

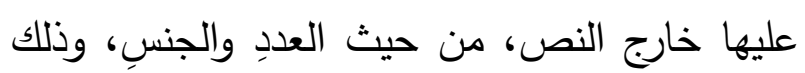

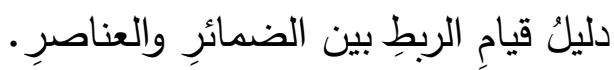

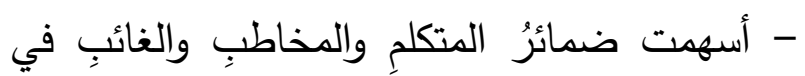
ربطِ لغةِ النصِ بسياقها، من خلال إحالتها إلى العالم الخارجي، وهذا جعلَ الاتصالَ قويًا وواضحًا ومباشرًا بين المحاورِ الرئيسة في القصيدةِ، وكان من أقوى ولهي

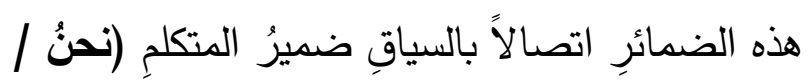

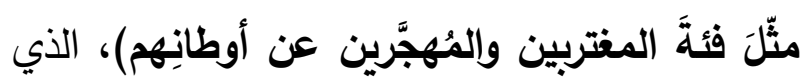

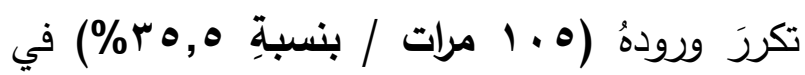
النصِ، وهو ربطَ النصَ بالسياقِ الذي حصلَ فيهِ. - قيامُ تفاعلٍ بين المتلقي ولغة نصِ القصيدةِ، بدليل مقدرتهِ على تحقيقِ إدراكنا للعناصرِ المُحالِ عليها

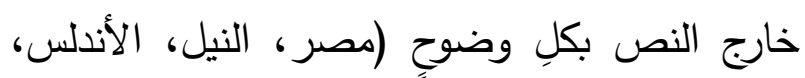

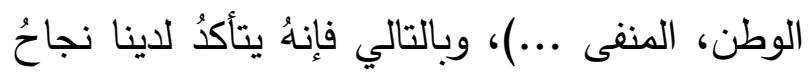

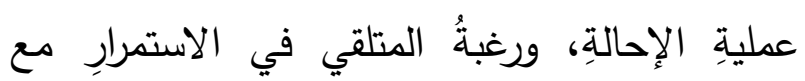
النصِ. - n - وردت أسماءُ الإشارةٍ بوصفها إحالةً إشاريةً في القصيدةٍ ككل في موضِّ واحدٍ فقط، في قولهِ: وهذهِ 
(0) عبد العظيم، فتحي خليل: مباحث حول نحو

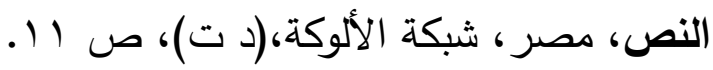
(ך) خطابي، محمد: لسانيات النص: مدخل إلى الى انسجام الخطاب، بيروت، لبنان، المركز الثقافي

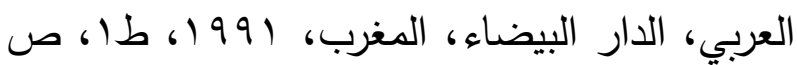
..0 *** مهنها نقل المعاني إلى كلمات والكلمات إلى أصوات أو كتابة. (V) لسانيات النص: مدخل إلى انسجام الخطاب،

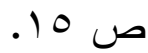
(^) عفيفي، أحمد: الإحالة في نحو النص، كلية

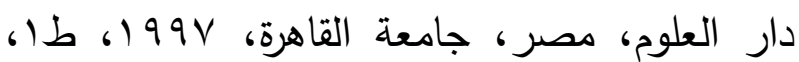
ص ص • מ

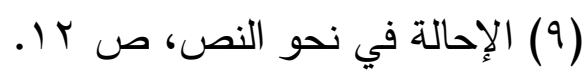

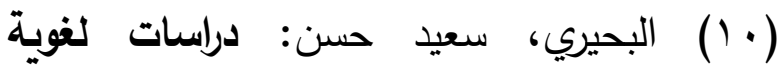

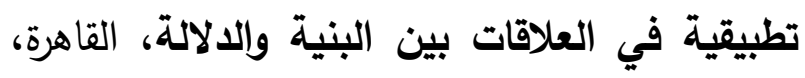

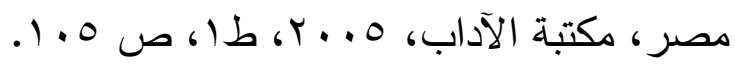

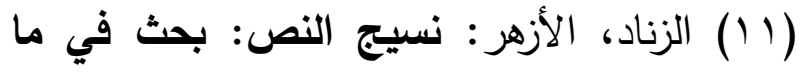
يكون به الملفوظ نصا، بيروت، لبنان، الدار البيضاء، المغرب،المركز العربي الثقافي، سو9 19، هول،

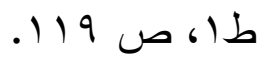

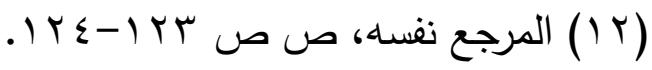

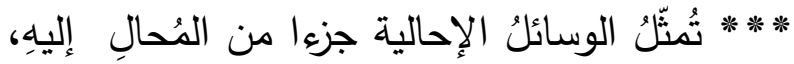

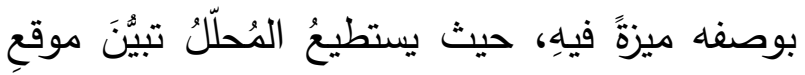
المُحال إليهِ من خلال هذه الوسائل الدالة، وعلاقتها

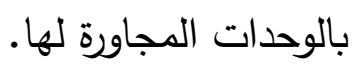

معناها، وذلك بإحداثِ التلاحمِ والترابِِ في سجيةٍ وهدوءٍ، من غيرِ أنْ يكونَ ذلكَّ لافتًا لانتباهِ القارئ. خلاصةُ النتائج:

الإحالة النصية بروابطها المختلفة حقَََّت الكفاءةً

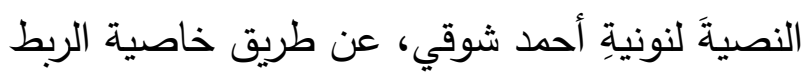
والتتسيق؛ لأنّ هذا الجانب من النظام التركيبي للغة مُهمته العمل على تحقيقِ ما نسميهِ الاتساق النصي.

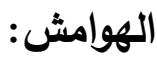

* شوقي، أحمد: الثوقيات: الأعمال الكاملة،

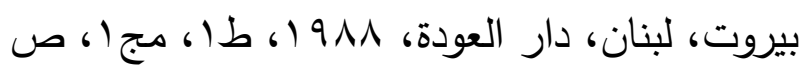

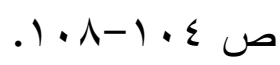
(1) الفراهيدي، الخليل بن أحمد: معجم العين، تح: عبد الحميد هنداوي، بيروت، لبنان، دار الكتب

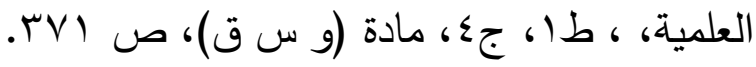

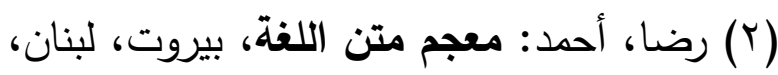

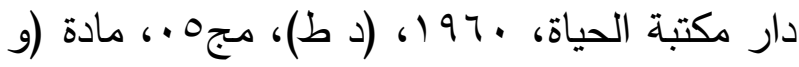

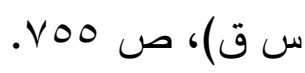

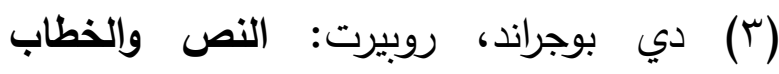
والإجراء، تر: تمام حسان، القاهرة، مصر، عالم

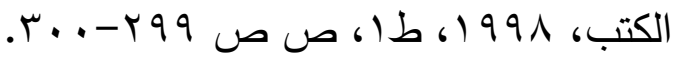
(ع) بشار ، إبراهيم: »الاتساق في الخطاب الثعري:

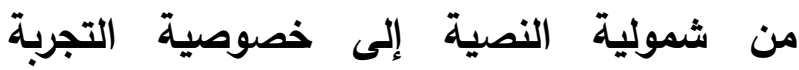
الثعريةه،، بسكرة، الجزائر، مجلة المخبر : أبحاث الفيه

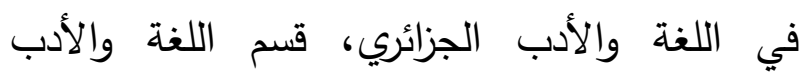
العربي، كلية الآداب واللغات، جامعة محمد خيضر،

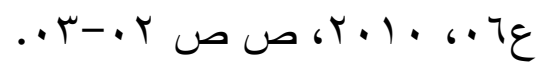


r. تهامي، الزهرة: الإحالة في ضوء لسانيات النص وعلم التفسير من خلال تفسير التحرير

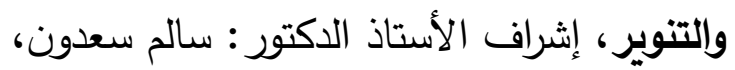

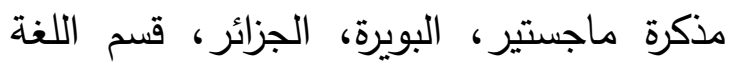

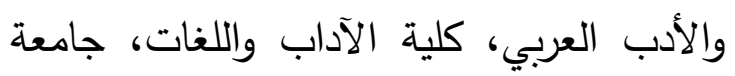

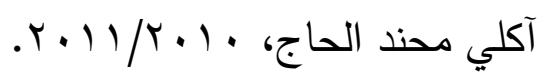

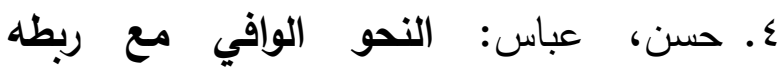
بالأساليب الرفيعة والحياة اللغوية المتجددة، مصر ، دار المعارف، (د ت)، طب.

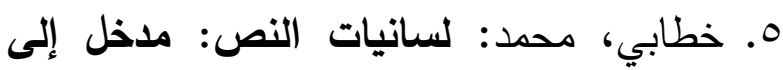

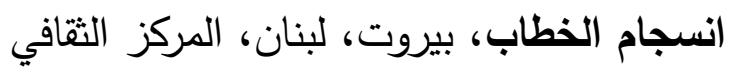

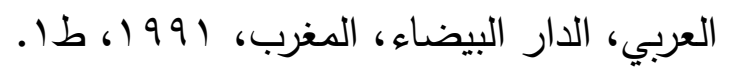

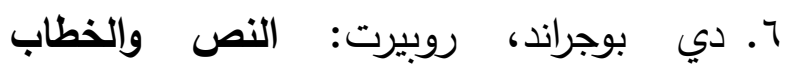
والإجراء، تر : تمام حسان، القاهرة، مصر ، عالم روبير الكتب، 1991 1، طا.

V. رضا، أحمد: معجم متن اللغة، بيروت، لبنان،

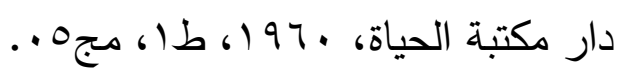

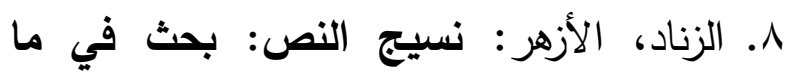

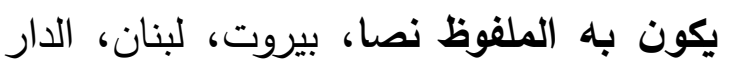

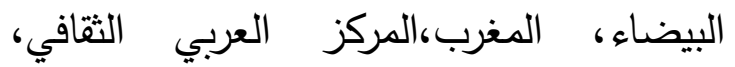

$$
\text { .19 199 }
$$

9. شوقي، أحمد: الثوقيات: الأعمال الكاملة،

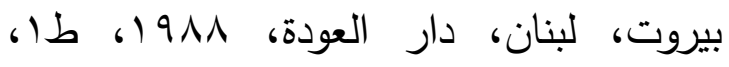

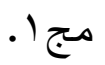

(T) (I) تهامي، الزهرة: الإحالة في ضوء لسانيات النص وعلم التفسير من خلال تفسير التحرير والتنوير، إشراف الأستاذ الدكتور: سالم سعدون،

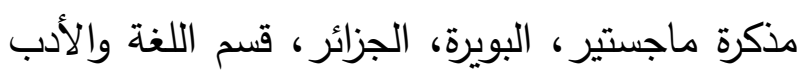

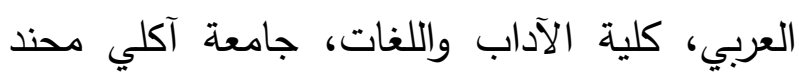

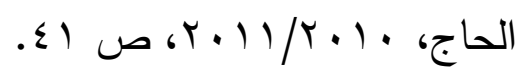

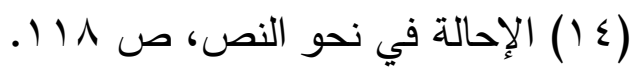

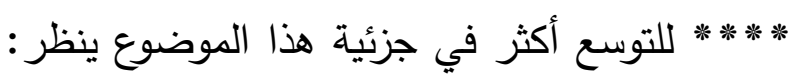
دي بوجراند: النص والخطاب والإجراء، الصفحات: I

(10) حسن، عباس: النحو الوافي مع ربطه

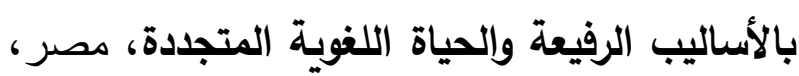

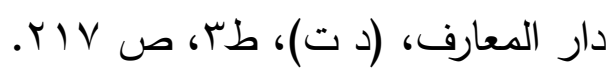

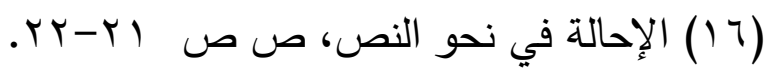

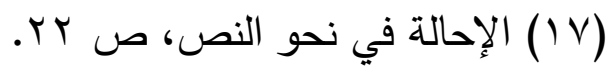
المراجع المصادر والمراجع: ا. بحيري، سعيد حسن: دراسات لغوية تطبيقية

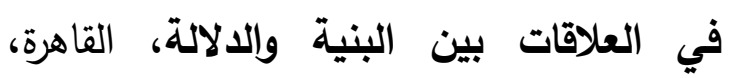

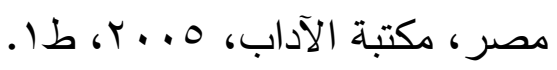
r. بشار ، إبراهيم: 》الاتساق في الخطاب الثعردي: من شمولية النصية إلى خصوصية التجربة الثعريةه،، بكرة، الجزائر، مجلة المخبر:

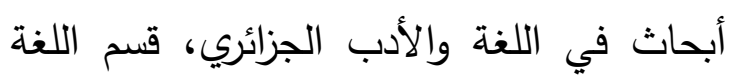
والأدب العربي، كلية الآداب واللغات، جامعة ولابل

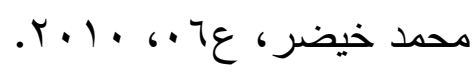




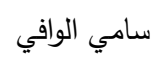

r ا. الفراهيدي، الخليل بن أحمد: معجم العين،

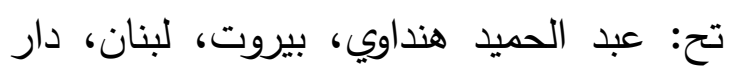

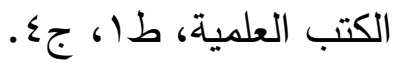

• النص، مصر، شبكة الألوكة، (د ت)، صبل، صباحل .11 11 . . عفيفي، أحمد: الإحالة في نحو النص، كلية

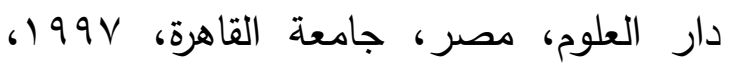
$.1 \mathrm{~b}$ 


\title{
Textual Cohesion and the Characteristics of assigning in the Poem of Ahmed Shawki "Andalusia" ( Linguistic Statistical study )
}

\author{
Dr. Sami Louafi \\ College of Letters. Laarbi ben mhidi \\ University. Oum Bouaghi. Algeria
}

\begin{abstract}
Abstarct. In this study we analyze a poetic model, represented in Ahmad Shawqi's poem "Andalusia," in which we focused on the reference links, as a fundamental criterion of textual consistency, which formed a strong presence within the text through its three types: (prior/post/ textual) , Reflecting the correspondence between the assigning parties of an assignor and an assignee.
\end{abstract}

Key words: Cohesion- Reference- Linguistic- Statistical- Andalusian Poem 